\title{
ESTUDIO DE LA MUJER RURAL Y EL DESARROLLO DEL CAPITALISMO EN EL AGRO COLOMBIANO
}

\author{
MAGDALENA LEÓN DE LEAL \\ Asociación Colombiana para el \\ Estudio de la Población \\ $y$ \\ CARMEN DIANA DEERE \\ Universidad de Massachusetts
}

\section{INTRODUCCIÓN}

EL OBJETIVO DE ESTE ENSAYO es presentar una orientación para el estudio del trabajo de la mujer rural, que mediante el análisis histórico y a partir de ciertas categorías permita conocer y entender la realidad actual. El trabajo se desarrollará en el caso concreto del estudio de la mujer rural colombiana, para lo cual se considera la división del trabajo por sexo y el desarrollo del capitalismo en la agricultura.'

Se parte de la idea de que el estudio de la mujer tiene que estar vinculado al estudio de la sociedad. La mujer y el hombre no existen desligados uno del otro; tampoco son actores individuales separados de la sociedad que los forma y que a la vez los abarca. Si bien es cierto que dentro de la orientación aquí propuesta no tienen mucho sentido los estudios que visualizan el problema estrictamente de sexo, tampoco se pueden aceptar como teóricamente válidos los estudios que separan el análisis del trabajo de la mujer del análisis histórico del desarrollo capitalista. Se está de acuerdo con la posición teórica que considera la opresión sexual de la mujer —o la subyugación al hombre — relacionada íntimamente con la explotación clasista. El estudio de las formas de reproducción patriarcal dentro de la sociedad debe analizarse dentro del contexto de la reproducción de las relaciones de clase de cada sociedad en particular.

En esta introducción se desarrollan algunos planteamientos que sirven de base para derivar proposiciones para el estudio de la mujer rural. La segunda parte presentará, junto con el diseño de la investigación, los rasgos históricos más generales del desarrollo del capitalismo en el agro colombiano y la articulación de diferentes regiones al proceso, con la intención de vincular su desarrollo histórico con el proceso de acumulación de

\footnotetext{
${ }^{1}$ El análisis que se realiza en este ensayo puede considerarse como preliminar, ya que se inscribe dentro de un proyecto de investigación en proceso. Para cada uno de los estudios de caso que aquí se presentan, se está realizando un análisis específico, mucho más elaborado y documentado que servirá para refinar las hipótesis enunciadas.
} 
capital y, a nivel de la unidad doméstica, con la división del trabajo por sexo como estrategia familiar. En la tercera parte, se concluirá con un resumen de los resultados del estudio del proceso colombiano en términos de los planteamientos presentados antes.

La división del trabajo por sexo se considera como una categoría descriptiva del trabajo ${ }^{2}$ que cumplen tanto hombres como mujeres en la sociedad. Se plantea como proposición central que la división sexual del trabajo refleja condiciones socioeconómicas concretas de la acumulación de capital, y en este sentido la división sexual del trabajo no está cultural o biológicamente determinada, sino más bien se encuentra en las bases materiales concretas. Es así como se supone que la división del trabajo por sexo es una variable dinámica que cambia con los cambios coyunturales de la estructura y organización de la producción. Por lo tanto, es necesario comprender la dinámica de la acumulación para apreciar las implicaciones que tiene la división del trabajo por sexo para la posición socioeconómica de la mujer.

La orientación que se pretende desarrollar vincula el trabajo de la mujer,, evidenciado en la división del trabajo por sexo, con el desarrollo de la sociedad en su conjunto mediante cuatro niveles de análisis: la relación de una sociedad nacional con el desarrollo del capitalismo a escala mundial; la integración regional dentro de una formación social; la integración del campesino a las formas de producción y extracción del excedente en cada región, y la dinámica interna de la familia campesina.

En términos más concretos, la tarea de este ensayo es identificar las tendencias generales de la forma de integración de un nivel a otro, en diferentes períodos de la historia nacional. En el nivel más general se puede plantear que el estudio de una formación social está inscrito dentro del estudio del desarrollo del capitalismo como modo de producción dominante a nivel mundial. Para cada formación social, históricamente se pueden identificar en un momento determinado las formas cambiantes de vinculación a través de la lógica y de las contradicciones de la acumulación de capital. Así una formación social puede estar inscrita como productora de materias primas, o de mercancías de consumo para la exportación, o también como mercado para las exportaciones de un centro dominante en un momento dado, o sujeta a la exportación de capitales del centro en otro momento.

Es importante destacar que la forma como se vincula una formación social tiene repercusiones determinantes para el mismo desarrollo del capitalismo como modo dominante a nivel nacional, y que en el nivel interno este desarrollo es un proceso de expresiones diferentes según sean las bases materiales. Es posible entonces, a nivel interno nacional, identificar diferentes procesos del desarrollo del capitalismo, que se visualizan como diferentes formas de integración de regiones a la economía nacional. Estas

\footnotetext{
La noción de trabajo implica tanto la producción de valores de uso como la de valores de cambio para la producción, así como también para la reproducción de la sociedad.
} 
formas de integración son evidentes esencialmente en el espacio y en el tiempo, como vinculaciones al mercado de productos, ya sea nacional o internacional, o a la formación del mercado de trabajo nacional como zonas que expulsan mano de obra libre. También se puede suponer que el desarrollo precario del capitalismo, aun en zonas que poseen un excedente local acumulado, permite que este excedente se destine para la expansión de otras regiones.

Sólo entendiendo las formas de integración en el nivel regional, se puede llegar a dar contenido a las formas particulares de las relaciones sociales de producción en las cuales participa el campesinado. El proceso del desarrollo del capitalismo en la agricultura implica en sí mismo el desarrollo de formas de producción capitalistas, basadas en la mano de obra asalariada y que tienen como expresión la proletarización campesina. Sin embargo, de ninguna manera este proceso es lineal o constante. Las relaciones de producción en el agro son variadas y responden a la necesidad cambiante y contradictoria en relación con el desarrollo de las fuerzas productivas de extraer el excedente. Por lo tanto, en un momento dado, se pueden identificar varias formas de integración a la acumulación de capital, formas que varían según las variaciones del capital y de esta manera con el conjunto y las alianzas de las clases dominantes. Una de estas formas de integración se da por el mercado de productos como productora de mercancías; otra podría ser la articulación al mercado de trabajo como proletarios o semiproletarios, o también en la articulación a través de la renta de la tierra cuando ésta se da en relaciones de producción no capitalistas.

Este ensayo propone que solamente estudiando los procesos de vinculación campesina a la extracción de excedente económico, se llega a comprender la realidad concreta de la familia campesina y por lo tanto de las estrategias de sobrevivencia,, evidentes en la división del trabajo por sexo.

Se parte de que los intereses de la clase dominante, como grupo, al tener ésta el control de los medios de producción, serán determinantes en la organización de la producción dadas sus necesidades de extraer excedente. Por lo tanto, la división del trabajo por sexo estará estrechamente relacionada con la necesidad de extraer excedente, dado el grado del desarrollo de las fuerzas productivas. De igual modo, dada la configuración de la organización de producción en relación con la mano de obra disponible, se establecen los parámetros de participación en el mercado de trabajo para la familia campesina. Estos parámetros son tanto económicos - tal como acceso a la tierra o al salario- como ideológicos - manifestados en las restricciones sociales sobre la participación femenina en actividades económicas. De todo lo anterior se puede concluir que la división del trabajo por sexo, cómo estrategia familiar,, no es una opción individual racionalizada, ni una respuesta mecánica y voluntaria. Puede estar enmarcada en el sistema valorativo dominante, internalizado a nivel familiar y personal, pero las raíces materiales están dadas como estrategias de sobrevivencia económica. 
El estudio de la división del trabajo por sexo rjermitirá poner en evidencia las implicaciones que de él se derivan para el análisis de la posición socioeconómica de la mujer en la sociedad. Y es así como en este ensayo se propone que para entender la situación socioeconómica de la mujer es necesario hacer un análisis de las condiciones objetivas que describen las leyes de movimiento de la sociedad, o sea el análisis de la acumulación de capital basado en el método del materialismo histórico.

\section{I . DESARROLLO CAPITALISTA EN EL AGRO EN CUATRO REGIONES DE COLOMBIA}

Antes de presentar los casos es preciso indicar someramente el diseño de la investigación ${ }^{4}$ de donde derivan los datos utilizados en este ensayo, así como también los rasgos más generales que caracterizan la entrada de la economía colombiana al mercado mundial y la formación del mercado interno.

\section{Diseño de la investigación}

El diseño de la investigación comprende tres etapas: análisis de la estructura agraria colombiana; estudios de caso regionales, y una tercera fase, aún en preparación para 1978, de carácter posiblemente cuantitativo mediante muestreo.

La primera etapa del análisis de la estructura agraria colombiana estaba encaminada a la selección de áreas para los estudios de caso regionales. Se seleccionaron áreas en donde el impacto del desarrollo del capitalismo tuviera expresiones diferentes. Así, fue preciso plantear los antecedentes históricos de la regionalización colombiana y a partir de ella caracterizar la estructura actual. ${ }^{5}$ En esta etapa se trabajaron los censos de población de 1964 y 1973 y los agropecuarios de 1960 y 1970 para 224 municipios del país que agrupados representaban 21 comarcas o regiones. ${ }^{6}$ Estas regiones a un nivel muy general presentaban diferentes grados de penetración del capitalismo. Así, había regiones de agricultura comercial más desarrollada con componentes de alta productividad y otras de estructura agropecuaria tradicional con componentes de baja producti-

" La investigación "Acerca del trabajo de la mujer en el sector rural colombiano" de la cual forma parte este trabajo, está financiada por donación de la Fundación Ford y la Fundación Rockefeller,

Esta investigación es dirigida por Magdalena León de Leal con la colaboración de Carmen Diana Deere como investigadora asociada.

"Un informe previo de la investigación, titulado "Configuración histórica y caracterización actual de sus expresiones regionales", consigna el análisis correspondiente a esta etapa del proyecto.

"Cada comarca tendía a dibujar unidades espaciales socioeconómicas de un tamaño intermedio entre la gran región geográfica y la unidad administrativa municipal y que a su vez compartía ciertas características físicas y económicas que permitían plantear una relativa homogeneidad. 
vidad. Por último, de las 21 regiones se seleccionaron cuatro, con la intención de obtener en los estudios de caso representación del componente de alta productividad en una región de agricultura comercial - caso de El Espinal en el Departamento del Tolima - y otra de cafeticultura con introducción de procedimientos técnicos — caso de Fredonia en el Departamento de Antioquia-; del componente de baja productividad en una región minifundista — caso de García Rovira en el Departamento de Santander del Sur-y otro de latifundio ganadero — caso de Sincelejo en el Departamento de Sucre (Véase el mapa 1).'

Este ensayo se refiere a la segunda etapa: estudios cualitativos de casos regionales. Éstos se llevaron a cabo en las cuatro regiones señaladas y las técnicas de recolección de los datos se resumen a continuación.

Los estudios de caso en cada región tenían como objetivo conocer la estructura actual. Para explicarla se trató de detectar algunos cambios que a través de la historia oral señalan variaciones históricas en las relaciones sociales de producción. Al igual que en los procesos de diferenciación y descomposición campesina, se dio especial énfasis al desarrollo del mercado de trabajo. Para lograr este objetivo se efectuó trabajo de campo en las cuatro regiones mencionadas por períodos de dos y medio a tres meses $^{8}$ El trabajo de campo estaba encaminado a conocer cualitativamente el proceso en cada región y a extraer los rasgos generales para su caracterización. Se aplicaron tres tipos de entrevistas no estructuradas o abiertas. Para entender el mercado de trabajo desde el punto de vista de la demanda se entrevistaron las empresas que, según la observación, podrían indicar la naturaleza de la producción en la zona.' Para entender el mercado de trabajo desde el punto de vista de la oferta se entrevistaron diferentes trabajadores de las empresas seleccionadas. Los trabajadores representan las diferentes tareas de la organización de la producción dentro de la empresa y se tomaron hombres y mujeres. ${ }^{10}$

Por último, en el tercer nivel, se entrevistaron las unidades familiares." Se procuró captar los diferentes estratos del campesinado y fue así como en cada región, después de conocer los elementos de diferenciación más característicos, se procedió a aplicar las entrevistas. Estos elementos varían localmente, pero en esencia están representados por el tamaño y la tenencia de la tierra, y por la venta o compra de fuerza de trabajo o grado

\footnotetext{
Estas cuatro regiones a su vez representaban un total de 54 municipios de los cuales se estudiaron sólo 20 por la imposibilidad de abarcar todos durante el trabajo de campo en los estudios de caso regionales.

s trabajo de campo se realizó en los meses de marzo, abril y mayo de 1977.

- En cada región se realizaron seis de estas entrevistas para un total de 24 en toda la investigación. Las empresas se seleccionaron con criterios cualitativos y se aplicó la Guía Núm. 1, "Entrevistas con dirigentes de empresas y/o haciendas", ACEP, 1977.

${ }_{10}$ En cada empresa seleccionada se aplicaron seis de estas entrevistas o sea un total de 36 entrevistas por región y de 144 en total. Se aplicó la Guía Núm. 2 , "Entrevistas con trabajadores de las empresas y/o haciendas", ACEP, 1977.

En cada región se entrevistaron 30 unidades familiares para un total general de 120 entrevistas. Se aplicó la Guía Núm. 3, "Entrevistas en la unidad campesina", ACEP, 1977.
} 


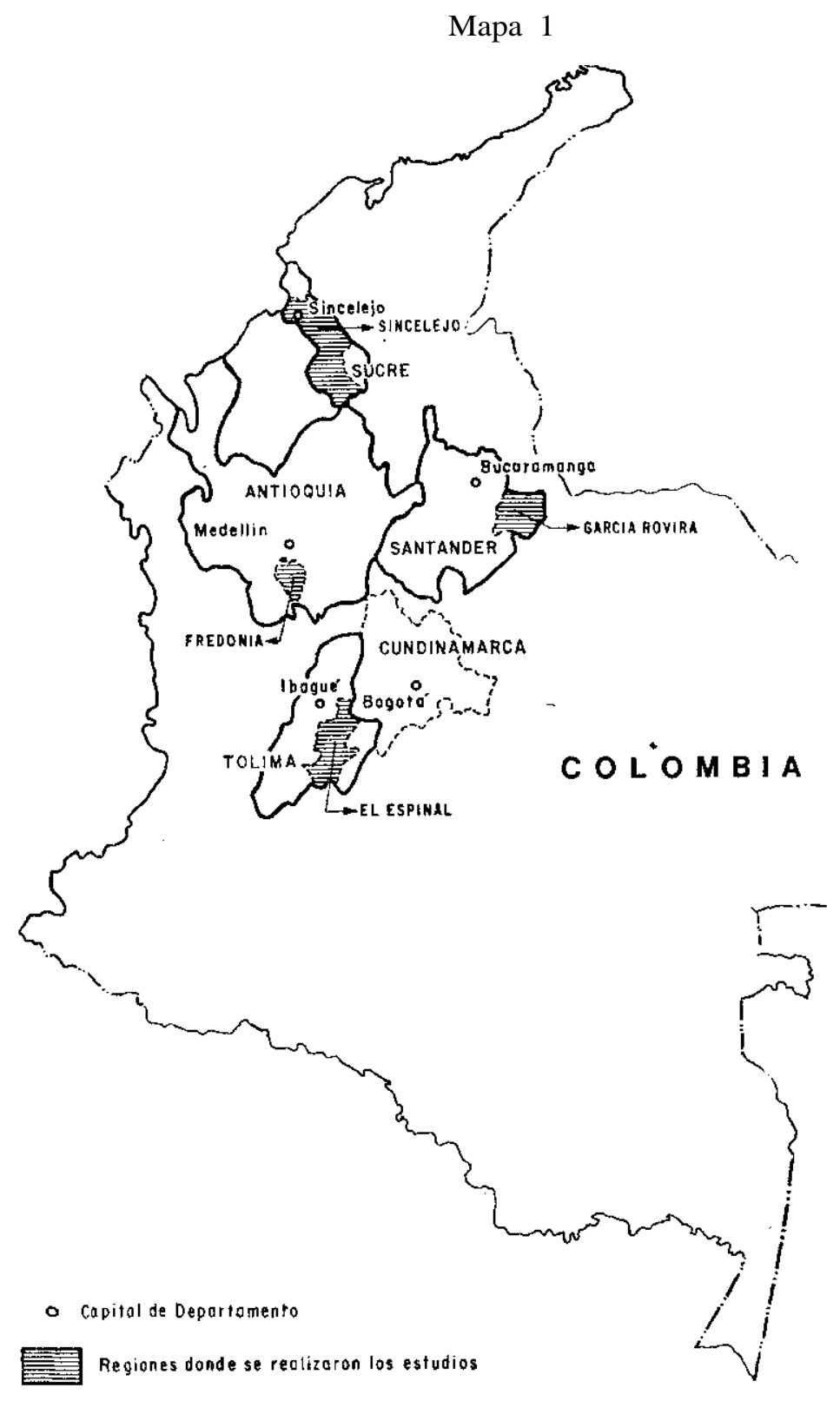


de proletarización. Los datos de estas diferentes fuentes de información primaria, además de análisis de datos secundarios y bibliográficos, son la base de análisis de los procesos de desarrollo del capitalismo y de la posición socioeconómica de la mujer que se presentan para las cuatro zonas señaladas. ${ }^{12}$

\section{Rasgos generales de la economía colombiana $*$}

En las postrimerías del siglo xix, el país se caracteriza por la incipiente formación de un mercado de trabajo y por una producción interna reducida que, en repetidas ocasiones y por medio de diferentes productos, busca abrirse paso al comercio exterior y de esta manera vincularse al capitalismo mundial. ${ }^{14}$ La dinámica de este mercado de productos y trabajo estaba íntimamente relacionada con la organización social de la producción característica de la época.

Hasta mediados del siglo xix, la organización social colombiana estuvo determinada por la herencia colonial y las modificaciones resultantes de las luchas independentistas; es así como continúa el "resguardo" indígena y la agricultura de subsistencia basada en la hacienda. Pero a mediados del siglo se dan cambios fuertes en la redistribución de la propiedad territorial con la abolición de los "resguardos", la adjudicación de baldíos y la desamortización de bienes de manos muertas. Al mismo tiempo, la abolición de la esclavitud en 1851 confluyó en la incipiente creación de un mercado de trabajo. La propiedad territorial se torna de tipo libremente enajenable y la mano de obra india y negra deja de ser básicamente atada, creándose un pequeño potencial de trabajadores agrícolas libres.

En los últimos decenios del siglo, el café aparece en el mercado de productos como la respuesta que va a orientar el proceso siguiente de in-

\footnotetext{
${ }^{12}$ Es importante anotar que para cada región existe, además de los datos consignados en las encuestas, un informe de campo detallado y, como ya se mencionó, que para cada región está en proceso un documento analítico detallado.

Con base en Jesús Antonio Bejarano "El fin de la economía exportadora y los orígenes del problema agrario", en Cuadernos Colombianos, Núm. 6, Añ̃o I I, segundo trimestre de 1975; Núm. 7, Año I I, tercer trimestre de 1975; Núm. 8, Ã̃̃o I I, cuarto trimestre de 1975. Orlando Fals Borda, Historia de la cuestión agraria en Colombia, Bogotá, Publicaciones de la Rosca, en especial el Cap. 7 y 8, 1975. Salomón Kalmanovitz, La agricultura en Colombia, 1950-1972, Bogotá Departamento Administrativo Nacional de Estadística-DANE, Boletín mensual de Estadística, Núm. 278, 1974. S. Kalmanovitz, Ensayos sobre el desarrollo del capitalismo dependiente, Bogotá, Editorial Pluma, 1977. Francisco Leal Buitrago, Social Classes, International Trade and Foreign Capital in Colombia: An Attempt at Histórica! Interpretation of the Formation of the State, 1819-1935, tesis doctoral, Wisconsin University, Madison, 1974. Hugo López, "La inflación de la década de los veinte", en Cuadernos Colombianos, Núm. 5, Año II, en especial pp. 43-139, Bogotá, 1975. Absalón Machado, Café: de la aparcería al capitalismo, Bogotá, Punta de Lanza, 1976. Víctor Manuel Moncayo "La ley y el problema agrario en Colombia", en Ideología y Sociedad, 14-15, julio-diciembre de 1975, en especial pp. 64-86.

${ }^{14}$ Se ensayaron varios productos de exportación en forma alternativa e infructuosa, como el tabaco, cuya producción tuvo auge entre 1855 y 1875 (en especial durante 1868-1872), la quina que se exportó principalmente en 1875 y 1881, y el añil, de importancia entre 1870 y 1875 .
} 
tegración nacional al mercado externo, así como también la dinámica interna del país como un todo y sus procesos regionales. Colombia se articula de una manera subordinada y dependiente dentro del proceso de reproducción y acumulación capitalista, articulación que se realiza mediante la exportación de un producto primario - el café- con destino al mercado mundial, y por la importación de bienes de consumo manufacturados.

Con el café la economía colombiana logra hacer corresponder al máximo sus posibilidades internas con los imperativos de la división internacional del trabajo. El café, cuyo cultivo se inicia a mediados del siglo xix (1830), tenía a finales del mismo un puesto de significación creciente en el comercio exterior, y para 1919 representaba ya el 69\% de las exportaciones. Es también por esta época que Estados Unidos adquiere un absoluto monopolio como comprador y vendedor para el comercio colombiano que satisface la demanda de su mercado interno con la importación de productos manufacturados.

La organización productiva del cultivo del café sirvió para generar un capital comercial que, a su vez, tuvo influencia en la formación de un mercado interno. La formación de este mercado, unido a otros factores, hizo posible en el decenio de 1930 iniciar el proceso de industrialización, proceso que, vinculado al desarrollo capitalista internacional, generó cambios en el desarrollo agrario nacional, los cuales se evidencian por la entrada y dominio de relaciones más abiertamente capitalistas en la agricultura actual.

La producción cafetalera se dio en manos nacionales y bajo dos formas principales: la gran hacienda cafetalera ${ }^{15}$ y la pequeña propiedad parcelaria. ${ }^{16}$ Esta última forma fue aumentando su peso relativo en la producción del grano desde principios de siglo, y para el decenio de 1930 constituía parte muy importante de la producción.

El auge cafetalero inició el primer proceso de desarrollo rural de importancia, sin embargo, cada una de las formas de producción trajo importantes diferencias para el desarrollo del capitalismo. La hacienda cafetalera fue explotada principalmente con base en el concierto agrícola, la aparcería y el arrendamiento de tipo precapitalista, dando origen a renta en dinero y en especie. La pequeña propiedad parcelaria dio lugar a la formación de unidades productivas de tipo familiar. Fue así como la base de la explotación de oriente dejó muy poco, tal vez menos que en occidente, en manos del productor directo. Además, en ambas zonas, el hecho de estar vinculada su producción al mercado mundial, hizo posible el desarrollo del capital comercial y del comercio en el país como una actividad fundamental de la economía. Así, las ganancias no quedaron en manos de

\footnotetext{
is Se localizó en el oriente del país: Santanderes, Cundinamarca, Oriente del Tolima, Cauca y Nariño. La región de García Rovira pertenece al oriente colombiano pero no está ubicada en la parte que constituyó la zona cafetera.

${ }_{16}$ Se localizó en el occidente del país: Antioquia, Caldas, Norte del Valle y Occidente del Tolima. La región de Fredonia es parte de la zona cafetera que se caracterizó por este tipo de producción.
} 
los productores directos —arrendatarios,, aparceros o unidades familiares- sino más bien terminaron en manos de los grandes cafeticultores y comerciantes. La extracción del excedente al cultivador directo se realizó por diferentes mecanismos, entre ellos la renta en trabajo y especie en la aparcería y el arrendamiento, o por el mecanismo de bajos precios para la producción familiar por medio de las trilladoras, anticipos de los compradores locales, los procesos de compra y las características monopólicas del comercio y el transporte.

Aun teniendo en cuenta el proceso de explotación al cultivador directo, el café imprimió una dinámica que fue fundamental en la formación del mercado interno, en cuanto generó demanda para ciertos bienes de consumo, fenómeno más importante en la región occidental,, donde la concentración del ingreso fue menos aguda. Esta demanda por parte de los productores directos se expresaba en bienes agrícolas y algunos manufacturados; sin embargo, se vio limitada a su vez por la existencia de la producción de "pancoger" y la sustracción del excedente que ejercían intermediarios y comerciantes. Los efectos de este proceso en el país sirvieron para promover la integración de otras zonas rurales a la economía nacional, así como también el estímulo del comercio para reforzar a los grupos de comerciantes y complementarios de base urbana. Por otra parte, el surgimiento del sector manufacturero también generó su dinámica y zonas de desarrollo agrícola diferente del café, aun cuando a escala nacional no tenían un papel dominante.

Además, la formación de un contingente disponible de trabajo asalariado había alcanzado un desarrollo apreciable, que se hacía evidente en el campo por la mano de obra disponible para la cosecha, así como también para la trilla, transporte y comercialización del café y en las zonas urbanas por la creciente concentración de la población en núcleos urbanos. A su vez, la construcción de la infraestructura de comunicaciones del país, financiada por el capital extranjero y representada en la construcción de carreteras, ferrocarriles e instalaciones portuarias creó, por una parte, trabajos que demandaban mano de obra y, por otra, significó la integración económica regional por lo que el sistema vial del país dejó de orientarse únicamente hacia el mercado externo.

Es así como la acumulación de capital en el país, que como producto del proceso cafetalero fue a parar a manos de comerciantes, estaba lista para emprender actividades diferentes de las comerciales, impulsando la apertura de nuevas esferas de inversión. Es en esta coyuntura que se da, por medio de la sustitución de importaciones, el proceso de industrialización de los años 30.

El desarrollo industrial, que significó un aumento en la circulación de mercancías, hizo posible la modernización de la producción agrícola y con ella los cambios en las relaciones de producción - formas de explotación de trabajo- así como también en los medios de producción - formas de tenencia de la tierra - para dar paso al desarrollo de la agricultura capitalista. 
La organización de la hacienda basada en relaciones de producción precapitalista era, por un lado, inconsistente con un desarrollo industrial toda vez que desvinculaba al productor directo del consumo de bienes al colocarlo fuera del mercado interno y, por otro, la mano de obra sujeta se contraponía a la necesidad de satisfacer las crecientes demandas de trabajo asalariado que requerían una fuerza de trabajo desligada de la tierra. Estas contradicciones llevan a cambios fundamentales en las relaciones de producción y en las formas de propiedad que la legislación agraria en los años 30 vino a confirmar o a constituir en ciertas zonas, pero no a exterminar.

Con estos cambios en marcha, la segunda guerra mundial trae efectos que conducen al despegue de la agricultura capitalista. La guerra trajo inflación y dificultades para incrementar la capacidad industrial. Las escasas divisas se utilizaron para los ramos de la producción que eran imprescindibles como materias primas de otras ramas: La industria nacional se vio obligada a ampliar su producción basándose en una mejor utilización del equipo instalado, fenómeno que la llevó a aumentar el consumo de materias primas agrícolas.

Un resumen de los factores que conjugados sirvieron para conformar el auge agrícola suficientemente sostenido y que se dan después de la segunda guerra durante los años 40,, lo presenta Salomón Kalmanovitz ${ }^{17}$ en los siguientes puntos:

a) Un auge industrial y de exportaciones que demandaba bienes agrícolas e inducía una sostenida alza de precios favorables a los agricultores;

>) El proceso conocido como la violencia que reduce los valores de la propiedad e incrementa su movilidad, así como también remata en algunos lugares con relaciones atrasadas de trabajo;

c) Una fuerza de trabajo desarraigada que contribuye a abaratar los salarios rurales y por ende a surtir de mano de obra barata a las explotaciones empresariales que se iniciaron en Valle, Tolima y Cundinamarca;

d) Una notable alza en la productividad surgida de los nuevos métodos y maquinaria para la producción.

Los cultivos que caracterizan el proceso de desarrollo de empresas capitalistas en el agro son: caña de azúcar, arroz, algodón, cebada y otros como sorgo, soya, ajonjolí y palma africana, de aparición más tardía. Esta agricultura capitalista se da en tierras planas y de planicie. En cuanto al mercado de productos se refiere, la agricultura campesina parcelaria fue bastante ajena a los inicios de este proceso y sólo cuando en el sector capitalista se empezaron a producir algunos de sus propios productos se resiente frontalmente. Su ligazón fundamental al proceso se da entonces

S., Kalmanovitz, "Evolución de la estructura agraria colombiana", en Cuadernos Colombianos, Núm. 3, año I, 1974, p. 271. 
a través del mercado de trabajo al generar mano de obra proletaria o semiproletaria barata.

\section{El proceso de la región de Fredonia}

Las precondiciones para el auge del cultivo de café se dieron en Antioquia, específicamente en la zona de Fredonia, en el siglo xix con el proceso de colonización de la frontera por parte de un campesinado libre, migrante, de origen español al igual que mestizo y negro, que buscaba nuevos filones de oro como alternativa a la explotación minera en parte agotada por la baja productividad, y tierras cultivables para establecerse. Esta colonización, en parte promovida por el Estado, al igual que vinculada a intereses mercantiles, hizo posible la formación de un campesinado medio en la zona al tiempo que favoreció la expansión de las haciendas, creando un relativo monopolio sobre la tierra en ciertas zonas. Las familias de campesinos desmontaban la selva y se establecían en núcleos de agricultores. Muchas veces la expansión fue financiada por el capital mercantil que proveía a los colonos con bienes de consumo durante el proceso y otras usaba el endeudamiento para acaparar tierras — una vez listas para la explotación agraria- - y especular con ellas. A medida que llegaban más colonos en busca de tierras, las haciendas fueron captando la mano de obra disponible para su expansión latifundista. Así se dio el proceso mediante el cual las tierras fueron dadas a familias campesinas para desmontar y sembrar sus cultivos por varios años hasta que el hacendado se apropiaba de ellas para la producción ganadera, moviendo la familia campesina aún más allá dentro de la selva. Como en otras zonas del país, recayó sobre la familia conquistar la naturaleza, dando paso a la futura expansión agrícola y ganadera y por lo tanto a la acumulación de la clase dominante.

En la época de 1870 se empezó a producir café, principalmente en haciendas. Al parecer la primera iniciativa para su cultivo partió de la clase terrateniente, pero rápidamente se incorporó a la producción en unidades campesinas, tal vez por la baja técnica y la escasa inversión requerida y dada la existencia de tierras aptas para su cultivo. Según las fuentes disponibles hay acuerdo en que por los años de 1920 la economía campesina estaba básicamente ligada a la producción del café y cada vez más subordinada al capital comercial.

A principios de siglo muchas de las haciendas de la zona de Fredonia se caracterizaban por la combinación dé diferentes tipos de contratos. En las primeras iniciativas del cultivo hubo contratación de mano de obra libre, al mismo tiempo que ya en este período se nota una elevada participación de mujeres y niños tanto en la cosecha como en el beneficio del café. Otra forma de producción fue la "compañía",, una variación de la aparcería. En una variante del arreglo, el campesino se encargaba de sembrar los árboles y con su familia hacer todas las labores del cultivo; la cosecha se dividía en partes iguales. Hubo casos en que después de algu- 
nos años, los campesinos eran trasladados a otras partes de la hacienda para empezar el proceso de nuevo. El hacendado pagaba las mejoras y la parcela pasaba a su administración directa. Otras veces el sistema de compañía se daba bajo la modalidad de entregar a la familia campesina una parcela con la siembra de café ya en producción y la familia debía cumplir con todas las tareas. La cosecha entonces se dividía en partes iguales. Parece que el primer sistema respondía a la falta de capital para expandir la producción cafetalera, y el segundo a la falta de mano de obra disponibles para cumplir con el alto requerimiento del cultivo del café. Es importante subrayar que ambas formas de captar el producto excedente recaían sobre la familia campesina en su integridad. La necesidad de una mano de obra disponible para la producción y beneficio del café aseguró la alta participación de la mujer, al igual que la del hombre y los niños, en el proceso de producción.

Coexistiendo con la aparcería se dio la expansión de la producción del café bajo la administración directa de la hacienda. En algunos casos fueron los mismos aparceros quienes pasaron a ser los "agregados" de la hacienda, aunque en otros casos los agregados tenían su raíz en campesinos sin tierra que venían a pedir trabajo. El sistema de agregados tiene como característica ser mano de obra asalariada, dándosele además de efectivo, como parte de su remuneración, el acceso a un terreno dentro de la hacienda para construir su casa y sembrar algunos productos de "pancoger". Este terreno, llamado cosechadero, era más grande que la reducida huerta que hoy en día tiende a caracterizar los contratos. De los sistemas mencionados, el más generalizado en la época anterior a 1960 era la participación permanente de los adultos como fuerza de trabajo de la hacienda para el cultivo del café: tanto hombres como mujeres se dividían en sus respectivas "cuadrillas" de trabajo. Al parecer, aun cuando las mujeres trabajaban en casi todas las operaciones del cultivo, el uso de mano de obra masculina era más común y los hombres trabajaban todo el año, ya fuera en el arreglo de la finca o en los trabajos más pesados del cultivo. Por lo tanto, podría pensarse que siendo la participación masculina más permanente que la de la mujer en las tareas del cultivo del café para la hacienda, una buena parte de la producción de "pancoger" en el cosechadero estuviera en manos de la mujer campesina. Las mujeres muchas veces eran acompañadas por sus hijos en el trabajo, y el tamaño de la familia era y sigue siendo condición favorable para entrar en la hacienda como agregado. Es interesante señalar que el pago del hombre casi siempre ha sido por día de trabajo, pero el salario de la mujer ha sido por tarea o a destajo. Ambos mecanismos funcionaron como incentivos en la colaboración de los niños en el trabajo de campo.

Según lo conocido de las relaciones de producción dentro de las haciendas cafetaleras, no se dieron relaciones estrictamente serviles, caracterizadas por el pago de la renta en trabajo sin remuneración. Una de las exigencias a los aparceros era la de trabajar un cierto número de días al año para el patrón, pero parece que siempre fueron asalariados. El arreglo 
con el agregado era que la mano de obra familiar estaría disponible para cumplir con las necesidades de mano de obra de la hacienda: el hombre como permanente y la mujer como permanente o temporal, pero tanto el uno como el otro remunerados en dinero, además de la parcela de subsistencia. Aun cuando al parecer las relaciones de producción se basaran en la venta de fuerza de trabajo, muchos aspectos patronales recaían sobre la familia campesina y en especial sobre la mujer. Así parece que sucedía y era principalmente la mujer campesina quien tenía que cumplir con los "favores para el patrón", fuera cocinándole a los obreros o a la familia del hacendado cuando estuvieran en la hacienda, lavando ropa, etc.

En la región de Fredonia parecería encontrarse internamente la presencia de dos zonas que permiten diferenciar algunos fenómeos. Auque cuando los aspectos sobresalientes del sistema de agregados en la parte de Fredonia y Venecia parecen haber servido para retener mano de obra, incluso con mecanismos extraeconómicos relativamente débiles, en otras zonas el proceso dinámico de minifundización creaba de manera constante una creciente masa de proletarios rurales expulsados por la presión sobre la tierra. Es así como, desde 1920, se aprecia una creciente descomposición campesina que para los años de 1940 se evidencia en términos de la composición de la población económicamente activa de algunos municipios de la zona. Zonas como Jericó y Támesis contaban con un buen grupo de obreros para las labores agrícolas y las de transformación, y los propietarios individuales agrícolas eran proporcionalmente menos.

También en este tiempo se dio la inmigración creciente hacia los centros urbanos. Tal es el caso de Medellín que experimentaba una creciente dinámica manufacturera y poblacional. También la proletarización del campesinado se hace evidente con el desarrollo de industrias de procesamiento del café y por el creciente número de fincas en vía de ser capitalizadas, al depender tanto las unas como las otras de una mano de obra libre para trabajos permanentes o temporales.

El período que se inicia desde finales del decenio de 1960 se caracteriza, aunque tardío en relación con otras zonas, por el aumento en la productividad que surge de la creciente tecnificación y capitalización del cultivo del café y por sus repercusiones en las relaciones de producción. En capacidad de líderes en este proceso estuvieron nuevos empresarios del agro que entraban arrendando tierras de hacienda, o comprando lotes de campesinos, para desarrollar en ellas la cafeticultura altamente tecnificada, cuya característica principal es la introducción del café caturra. Al lado de este proceso también se debe subrayar el proceso dinámico de diferenciación campesina. Pues el mismo no sólo se caracterizó por la descomposición del campesinado, donde pequeños agricultores en el transcurso de dos generaciones se convirtieron en proletarios sin tierra,, sino también porque la misma dinámica del café ha dejado que campesinos proletarizados por medio de sus ahorros o por la posibilidad de capitalizar a través de la aparcería en compañía compren tierras, volviéndose campesinos pequeños y medios, y hasta grandes en términos del terreno disponible. Así, 
el proceso del auge del café parece destacarse por el boom en el mercado de tierras y la posibilidad dinámica de integración vertical en el proceso productivo. Otra característica sobresaliente de la zona es que fincas de todo tamaño se especializan en la producción del café: la economía campesina, tal como la empresa capitalista o la hacienda en vía de capitalizarse, están completamente ligadas al mercado de mercancías, a su vez sujetas al capital comercial, sea pequeño burgués o gran capital nacional.

En líneas muy generales, hoy día, la estructura agraria se conoce por la siguiente división social y sexual del trabajo. Existe una alta concentración de productores de café en fincas subfamiliares, en lo que se puede llamar microfundios (menores deV4 de hectárea), que a la vez que producen café como mercancía, venden su fuerza de trabajo. Los hombres forman parte de la masa de trabajadores rurales que venden su fuerza de trabajo durante todo el año en sucesivos trabajos de tipo temporal. El pequeño microfundio cafetalero, asimilable a una huerta, cae bajo la dirección de la mujer que a su vez forma parte de la reserva de mano de obra para el cultivo del café comercial,, participando en determinadas épocas como la de cosecha. En los minifundios cafetaleros (mayores de 1 hectárea) la producción tiende a estar bajo la responsabilidad del hombre, aunque la mujer y los niños participan en las tareas que demandan bastante mano de obra. Dentro de este grupo la proletarización del hombre es casi permanente, quedándose en su parcela sólo cuando el trabajo en la misma lo requiere y la participación femenina como jornalera es menor.

En el grupo de los campesinos medios es donde el hombre puede dedicarse casi en exclusiva al cultivo del café además de la producción de algunos productos de "pancoger". Este estrato necesita contratar mano de obra asalariada para las diferentes tareas intensivas en mano de obra. La participación femenina está más ligada a los procesos de beneficio del café, como la selección, y su participación en trabajos de campo sólo se da en épocas de cosecha.

En el estrato de campesinos ricos todavía se encuentra la familia como unidad de producción, pero podría pensarse que la participación de mano de obra asalariada aumenta de manera creciente. En varios aspectos referentes a las formas de producción, este sector es igual o similar a las fincas capitalistas, tal vez los orígenes de clase social distinguen culturalmente a los campesinos en vía capitalista, producto de la diferenciación campesina, de la pequeña burguesía de origen urbano, la cual con capital originado fuera del agro ha entrado a invertir en el cultivo del café. La participación de la mujer en el trabajo agrícola de este sector se vuelve nula a medida que el mismo trabajo del hombre disminuye y las labores se realizan con mano de obra contratada.

Las fincas capitalistas se caracterizan por la poca mano de obra permanente y el uso de gran cantidad de mano de obra temporal. Los trabajadores asalariados casi nunca viven dentro de la explotación, más bien se abre paso el sistema de contratistas que se encargan de la contratación y, en algunos casos, de la supervisión de campo de la mano de obra. Tam- 
bien se dan contratos muy cortos de jornal pagado por día. En las haciendas cafetaleras también se observa tanto una creciente reducción, aunque todavía participa de la mano de obra permanente,, como el incremento en el uso de la mano de obra temporal. Las cuadrillas de mujeres son ya un recuerdo del pasado y el alto uso de mano de obra femenina se restringe a la cosecha del café y sólo hasta cierto punto participa en la selección. Entre los factores que se reportan como influyentes en este cambio están las leyes laborales que exigen pago igual a las mujeres y a los hombres. El trabajo asalariado femenino se define por la forma de pago a destajo - ya sea por cantidad de producto cosechado o recogido, o por el lote de siembra asignado para una tarea dada. El trabajo de los niños es aún complementario al de la mujer y por lo tanto el aporte al ingreso familiar depende de la cantidad de mano de obra con que la mujer puede contar.

Se puede resumir al hacer la proposición de que, tanto dentro de las haciendas como en las empresas capitalistas, la mano de obra femenina tiene el carácter de reserva de mano de obra para tiempos de alta utilización de trabajo manual o cuando la mano de obra masculina se reduce. Este último factor es más evidente en zonas proveedoras de mano de obra masculina para otras zonas cafetaleras del país que carecen de suficiente mano de obra. Los hombres son contratados con salarios por encima de los locales, por lo tanto la participación femenina local en la cosecha tiende a aumentar, reemplazando a los hombres, pero con sueldos más bajos. Se podría señalar también que las necesidades materiales, ya sea de sobrevivencia campesina o del mercado de trabajo, se reflejan a nivel ideológico en los valores trasmitidos de lo que es o no aceptable como trabajo femenino. En zonas donde en épocas anteriores la producción se caracterizó más por la unidad familiar como unidad de producción, la mujer no salía a trabajar fuera de la parcela. El proceso de descomposición campesina es reciente pero muy intenso y requirió sólo en los años recientes la iniciación de la proletarización femenina debido a necesidades económicas, y el trabajo de la mujer como asalariada es calificado negativamente, hasta identificar a la mujer asalariada como prostituta. ${ }^{18}$ En zonas donde el trabajo de la mujer como asalariada se remonta a varias generaciones, el trabajo de la mujer en el café hoy en día no atrae ninguna atención especial. Que la división del trabajo por sexo es cambiante y tiene su raíz material lo ilustra la siguiente cita de la zona donde más migración temporal masculina hacia otras zonas ha ocurrido: "hace unos 17 años la mujer no entraba a los cafetales porque se decía que apestaba el café; ahora no, la mujer trabaja igual que el hombre".

Si bien la acumulación de capital ha dependido de la explotación de la mano de obra familiar, también es cierto que las modalidades de la división del trabajo por sexo ha sufrido cambios que reflejan sus condiciones. Del lado de la familia campesina, igual que la familia rural proletarizada, la participación familiar proletaria está basada en la pobreza rural

${ }^{18}$ Es de resaltar que esta zona registra elevado nivel de prostitución, al tiempo que existe una fuerte influencia religiosa. 
y en la necesidad de recurrir a la participación plena de hombres, mujeres y niños para lograr la reproducción familiar.

\section{El proceso de la región de Sincelejo}

La región de Sincelejo, en la Costa Atlántica, estuvo vinculada primero a la economía regional y después a la nacional debido a la expansión de la ganadería extensiva. El latifundio ganadero priva en la organización de la producción, incluso hasta la época actual en la que la introducción de cultivos comerciales ha impulsado la capitalización de las haciendas y la proletarización de la mano de obra campesina.

El siglo xix se caracterizó por la formación en parte, y también por la expansión, de las haciendas ganaderas cuyos orígenes datan de la época colonial. El proceso de expansión fue llevado a cabo por la clase terrateniente, de manera principal con el confinamiento de mano de obra a la tierra para abrir la frontera. Esta clase propietaria de tierra hace valer este derecho a medida que la conquista de la naturaleza le da un valor incorporado a los terrenos y se constituye así la base para el monopolio sobre los medios de producción. Las familias campesinas, para conseguir acceso a la tierra, tuvieron que entrar en relaciones no capitalistas de producción. El sistema más común, de desaparición muy reciente, se denominó "monte por yerba". A la familia se le asignaba un lote de monte para que lo limpiara; podía sembrar cultivos de "pancoger" y después de unas cuantas cosechas debía devolver el lote en pastos y pasar a realizar el mismo proceso en otro terreno. El terreno habilitado era ocupado por el hacendado para la cría de ganado.

En la segunda parte del siglo xix se introdujo en la zona el cultivo del tabaco y tal vez en algunas haciendas se combinó su cultivo con la ganadería extensiva. El hacendado daba terrenos a campesinos para sembrar principalmente tabaco y la renta de la tierra se pagaba con lo que se denominó "el mejor corte". Al principio no era una cantidad fija, dependía de la cosecha, pero el mejor tabaco pasaba a manos del hacendado/Después se fijó la renta en términos absolutos, por ejemplo, 100 kilogramos por hectárea,, etc. El mismo terrateniente comercializaba la producción, y así la familia campesina se veía obligada a vender toda su producción a la hacienda. Este hecho también influyó en el patrón de producción del campesino independiente de la hacienda, ya que al tener un mercado estable para el producto tenía que venderlo a los precios fijados por el terrateniente, con lo que favorecía la acumulación de capital realizada con base en la explotación del trabajo familiar. Con el auge del tabaco surgieron también pequeños talleres familiares que lo procesaban haciendo cigarros como producto final. Las mujeres de la zona de Ovejas relatan que desde niñas iban aprendiendo este arte, en algunos casos procesaban la producción familiar y en otros los insumos que daban los pequeños comerciantes.

La producción de tabaco también contribuyó a la expansión de la hacienda por mèdio del sistema de "avances" (anticipos) que los hacendados 
daban a los pequeños productores independientes. La familia dedicaba su terreno a la producción tabacalera y para las necesidades alimenticias dependía de los avances de productos comestibles que les proporcionaba la cosecha o los escasos comerciantes locales. Cuando la cosecha no era buena, la familia quedaba endeudada y si no tenía animales para pagar, perdía su tierra. Posiblemente el endeudamiento reforzó el sistema conocido en la zona como "concertaje", el cual se da principalmente en las haciendas ganaderas y tal vez se desarrolló a partir del concierto forzoso que siguió a la esclavitud y que posiblemente se mantuvo por el mecanismo de las deudas sucesivas. El sistema se caracterizó por campesinos desposeídos de tierra que trabajaban tiempo completo para el patrón recibiendo como remuneración su sustento y sin tierra en usufructo. Sólo por un favor especial del patrón conseguían "su patio" para la huerta familiar y la cría de animales. Es posible que al trabajar el hombre tiempo completo, este patio fuera cuidado por la mujer, y de esta manera el hacendado rebajaba los costos de mantener su concertado. También se dio el sistema de arriendo de tierras caracterizado por el pago de renta en especie y en trabajo. A la familia campesina se le daba acceso a una parcela en forma estable, y la obligación para el hombre era trabajar sin pago uno, dos o tres días a la semana para el patrón, casi siempre en el cuidado del ganado. También hubo familias que recibían tierra, en especial para cultivos de tabaco, y pagaban en especie el arriendo. Esta forma ha sido confundida con el sistema de aparcería,, pero más bien representa un arriendo en especie. Se puede suponer que la producción dentro de la parcela dependía del esfuerzo productivo de toda la familia, y aun cuando hubo trabajo sujeto a la explotación directa, éste recaía sobre el hombre. Además de las obligaciones formales sobre el hombre, la importancia de mantener buenas relaciones con el hacendado requería que la familia campesina diera con regularidad "regalos" de vitualla al terrateniente, al mismo tiempo que la venta de hijas al patrón cuando estas eran solicitadas. También se dieron casos en que la familia campesina era obligada a comprar sus bienes en la bodega del patrón a precios muy por encima de su valor, lo cual funcionaba algunas veces como mecanismo de endeudamiento y por lo tanto de estrategia para fijar la mano de obra a la tierra.

Las diferentes combinaciones de pago de renta por la tierra, en trabajo o en producto, caracterizó las relaciones de producción en la zona hasta bien entrado el presente siglo. Como se puede destacar, la apropiación del trabajo excedente se basó en la familia campesina como unidad de producción, sujeta a la explotación directa o indirecta, lo que a su vez constituyó la base para la acumulación de capital. Parece que los primeros rasgos de la coyuntura actual, caracterizada por una creciente capitalización de las haciendas y la formación de un grupo proletario, se dieron con posterioridad a la segunda guerra mundial, dado el estímulo a la producción de algodón que resultó de la política de sustitución de importaciones.

Esta coyuntura significó por un lado la expansión del mercado interno y dio pie para la entrada de nuevos capitales al agro, al tiempo que con- 
dujo a la expulsión de los arrendatarios de las haciendas. Sólo hasta las postrimerías de los años cincuenta se nota la entrada de nuevos empresarios al agro a través del arriendo de tierras de haciendas, en especial en la zona de San Pedro, para la explotación de algodón. Durante este período también se nota el cambio del pago de arriendo de tierra, que antes se hacía en especie o trabajo, a pago en dinero. De singular importancia para la región ha sido el efecto de la reforma agraria de 1961. Por un lado se dividen algunas haciendas, dando paso a un mercado de tierras más ágil que propició la creación de fincas potencialmente explotadas, por su tamaño, para la agricultura comercial, aun cuando las tierras divididas muchas veces quedaron en manos de una misma familia. Por otro lado, el desarrollo del mercado de tierras impulsado por el alza en el valor de la tierra, al cambiar la productividad y la amenaza de la reforma agraria, impulsaron el lanzamiento de campesinos de las haciendas. La nueva coyuntura política dio paso a una importante organización campesina que inició reivindicaciones por la tierra y se negó al pago de renta. Este factor aceleró los lanzamientos y dejó en las haciendas una pequeña fuerza de trabajo permanente y asalariada.

Fue también con esta coyuntura cambiante de los años de 1960 que se dio la expresión de la industria semiprocesadora y exportadora de tabaco con base en inversión de capitales extranjeros. La entrada de las compañías extranjeras tuvo mayor significado para la pequeña burguesía comercial que fue paulatinamente desplazada, así como también la industria casera de producción de cigarros. En la zona tabacalera de Ovejas entraron procesadoras y empacadoras de tabaco que dependían de un proletariado dispuesto a trabajar cinco meses del año en forma continua. Las mujeres que antes cumplían con la producción artesanal,, se proletarizaron, ya que la industria siguió reclutando mano de obra femenina.

La gran expansión del algodón en los años de 1960 creó la necesidad de una abundante mano de obra temporal para tareas intensivas como los desyerbes y la cosecha. Esta mano de obra provino en gran parte de los campesinos lanzados de las haciendas, integrantes del proletariado rural de la zona, y que vivían en sitios semiurbanos. Fue por una aguda presión sobre la tierra que se dieron las invasiones campesinas de los años 1971 y 1972, y que llevó a la intervención del INCORA (Instituto Colombiano de Reforma Agraria) y a la reciente formación de empresas comunitarias por todo Sincelejo. ${ }^{19}$

La estructura agraria actual se caracteriza por una creciente concentración de capital en empresas agrícolas de cultivos comerciales tales como algodón, arroz y ajonjolí que funcionan junto con la ganadería, en vía de tecnificación. El proceso de diferenciación campesina polarizó la po-

\footnotetext{
${ }^{19}$ Sincelejo es la comarca con más empresas comunitarias en todo el país. Estas se formaron por iniciaitva del Estado y representan una forma de organización de la producción basada en el uso comunitario de la tierra y cuyo funcionamiento está en manos de los campesinos asociados y es supervisado por representantes de los organismos estatales.
} 
blación entre un pequeño grupo con acceso a tierras y una mayoría que paulatinamente sobrevive de la venta de su fuerza de trabajo. A diferencia de otras zonas, la producción de cultivos comerciales se concentra en las haciendas capitalizadas y en las nuevas empresas capitalistas, ya que el campesino con tierra sigue ligado en esencia a la producción de tabaco y de productos de "pancoger".

En el estrato de campesinos altos, con más de 7 hectáreas, sus antepasados fueron parte de las haciendas, siendo este grupo campesino el que tuvo éxito en lograr comprar tierras, pasando de arrendatarios a propietarios. Este grupo se distingue por la combinación de sus actividades en la ganadería y la agricultura produciendo tabaco, productos de "pancoger" y un poco de algodón. Debido a la extensión de sus tierras, emplea bastante mano de obra asalariada, principalmente masculina. Las mujeres de este estrato no participan en el trabajo agrícola de campo, pero sí en muchas actividades relacionadas con el tabaco, como los semilleros y la recolección y ensarte del producto.

Las tomas de tierras y la constitución de empresas comunitarias dieron salida a un campesinado independiente capaz de cubrir gran parte de sus necesidades de subsistencia y complementarlas con producción de tabaco y ganado. En este grupo se caracteriza el trabajo asalariado para la empresa con la cría de ganado como actividad masculina (incluido el ordeño), con la mujer encargada de la huerta y parte de la mano de obra familiar para el tabaco y, en medida más reducida, para la producción de alimentos tales como la yuca, el maíz, etc.

El campesinado bajo está en su mayoría formado por proletarios o semiproletarios, con acceso a parcelas por el arriendo en especie a campesinos de estratos altos. Este arreglo está muy ligado a la producción de tabaco, producto apto para la explotación familiar debido al elevado requerimiento de mano de obra. El empleo principal de este proletariado se encuentra en el algodón y en el tabaco. Así, tanto las mujeres como los hombres participan de las cosechas que son remuneradas a destajo y de esta manera absorben la mano de obra de toda la familia.

\section{El proceso de la región de El Espinal}

Uno de los mejores ejemplos de lo que ha significado el desarrollo del capitalismo en la agricultura lo proporciona el estudio del proceso en la comarca de El Espinal en el Tolima.

A comienzos del siglo xx esta zona se caracterizaba por el dominio de la gran hacienda ganadera. La producción ganadera se orientaba hacia el pequeño pero creciente mercado nacional y se complementaba por la producción de "pancoger" llevada a cabo por un campesinado sujeto a relaciones serviles de producción, medio por el cual podía tener acceso a la tierra. El monopolio de la clase terrateniente sobre la tierra fue la base para que la hacienda ganadera asegurara una fuerza de trabajo para abrir la frontera que la expansión ganadera requería. Así se dio el arreglo conocido 
como "los comunes", por el cual el terrateniente daba a campesinos acceso a tierra para sembrar dos o tres veces cultivos en el mismo lote, al cabo de los cuales se obligaban a devolver la tierra con pastos. Fue así como recayó sobre la familia campesina la lucha contra la naturaleza y para el hacendado significó la valorización creciente de la tierra apta para la ganadería extensiva.

En combinación con los comunes, y como forma progresiva de captar la extracción de plus trabajo, este período también se caracterizó por el pago de renta en trabajo apropiado directamente por el hacendado para su producción. El jefe de familia estaba sujeto a trabajar un número fijo de días sin pago para el hacendado a cambio de tener acceso a la tierra en forma estable, vivir dentro de la hacienda, tener derecho a casa, a tierras aptas para los cultivos de "pancoger" y algunas veces a ganado suelto en las tierras de las haciendas. La obligación era muy variada, de ocho días al año a un tope máximo de tres días a la semana. Se podría pensar que el número de días sujeto a la apropiación directa del hacendado variaba con la cantidad de tierra en posesión por el campesino o el número de animales que criaba, así como también con el tipo de relación entre el terrateniente y el campesino.

Cuando la mujer campesina no tenía un hombre para cumplir con la obligación de trabajo para el hacendado - obligación que casi siempre se relacionaba con el cuidado del ganado y obras de construcción e infraestructura en la hacienda- ella cumplía con la obligación trabajando para el hacendado en labores domésticas. Ésta parece ser la forma en que se estableció una división del trabajo por sexo en la explotación de la hacienda que asignaba a la mujer trabajos parecidos a los que le correspondían en la producción y reproducción de la fuerza de trabajo en el hogar campesino, y al hombre los trabajos que requerían bastante esfuerzo físico para la producción directa de la hacienda. Dentro de la unidad campesina, dedicada a la agricultura de "pancoger", la mano de obra familiar era la base de la producción, posiblemente con menor grado de diferenciación sexual en las actividades de producción de subsistencia. Se puede suponer que la participación de la mujer en la agricultura estaba relacionada con las exigencias del hacendado a los hombres en cuanto al pago de la obligación y con la intensidad misma de la producción.

Además, en este período también se dio, aunque en menor escala, la aparcería dentro de las haciendas, conocida como "la parcela". Lo que se conoce de estos arreglos indica que la familia ponía todo el trabajo para los cultivos de "pancoger" y si el terrateniente daba los insumos además de la tierra, la producción se dividía en partes iguales. Cuando el campesino ponía los insumos, la producción se dividía en tercios, una parte representaba la renta de la tierra, otra la reproducción de la mano de obra, y la tercera la reproducción de los medios de producción. Este sistema algunas veces también requería de obligaciones en trabajo por parte del hombre, aunque los días pagados eran menos que cuando la renta en trabajo era la única forma de extracción del excedente. La distinción fundamental en 
la renta en productos y la renta en trabajo estaba en que en la primera la familia entera estaba sujeta a la apropiación del plus trabajo en cuanto participaba en forma directa en la producción agrícola.

Al parecer, en la medida en que el valor de la tierra era bajo y la mano de obra campesina no era abundante, la fuerza de trabajo se mantenía mediante la cesión de tierras en usufructo al campesino. Además, dado el bajo nivel del desarrollo de las fuerzas productivas, la acumulación dependía de la fuerza de trabajo disponible y de la renta que se le podía extraer en términos de plus trabajo o plus producto absoluto. Estas condiciones de acumulación por la clase terrateniente iban a cambiar de manera drástica después de los años veinte.

Los pasos iniciales hacia el desarrollo de una agricultura comercial a nivel nacional, como ya se mencionó, se dieron en el período de la primera posguerra mundial, con el estímulo a las industrias nacionales como respuesta a la crisis en el comercio internacional. El incipiente desarrollo del mercado nacional, estimulado también por la creciente proletarización de la mano de obra, significó un aumento en la demanda de productos alimenticios. Esta coyuntura, prevista a nivel político en las leyes agrarias de 1905, 1926 y 1936,, empujaría al surgimiento de relaciones capitalistas de producción.

En la zona de El Espinal los primeros cambios notables se dieron en la siembra de cultivos como algodón (para la industria textil nacional) y arroz. A medida que se expandían los cultivos comerciales, se inicia el desalojo de arrendatarios en algunas haciendas. Sin embargo, el cambio más notable en la época fue el reemplazo de renta en trabajo por renta en efectivo. Este cambio puede enmarcarse dentro de la coyuntura general de la economía nacional que va en contra de las relaciones de producción precapitalistas en el campo.

El cambio definitivo hacia una agricultura capitalista caracterizada por empresas capitalizadas y tecnificadas, con uso de mano de obra asalariada, sólo se puede ubicar en el decenio de los años cuarenta. Sobresaliente para la zona fue la política de sustitución de importaciones después de la segunda guerra mundial. El estímulo por parte del Estado a la industria textil nacional tuvo importantísima repercusión para la producción de algodón. La producción de algodón, seguida rápidamente después de 1952 por el incremento en la producción de arroz, sorgo y ajonjolí, productos también destinados a la agroindustria, fue una respuesta a la política de precios y subsidios estatales.

La rentabilidad de la producción agrícola comercial tuvo gran impacto para el mercado de tierras, así como también para la tenencia de la tierra. El alto costo que adquiría la tierra fue la condición necesaria para la parcelación de las haciendas y la entrada de un nuevo grupo empresario al agro tolimense. Este grupo empresario tuvo sus raíces en la pequeña burguesía local (técnicos y profesionales), además de migrantes a la zona que veían en las tierras planas del Tolima la posibilidad de lucro. Muchos de éstos empezaron con tierras arrendadas en las haciendas, pero en la 
medida que su acumulación les permitía, algunos compraron lotes, con lo cual se cambió la estructura agraria local.

En términos de las relaciones de producción, el efecto más sobresaliente del proceso de desarrollo del capitalismo en la agricultura fue la formación de un proletariado agrícola. Este proletariado surgió a raíz de los cambios en la estructura de la demanda del mercado interno y por lo tanto de la tenencia de la tierra. Con la posibilidad de ganancias elevadas en la agricultura comercial tecnificada y con la empresa de tipo lucrativo, la acumulación no dependía sólo del trabajo humano como en la etapa inicial. En vez de una fuerza de trabajo atada a la tierra, lo que se requería - además de mano de obra libre - era tierra libre para la producción directa y altamente mecanizada. El peso de este cambio cayó sobre la familia campesina que fue sucesivamente desposeída de sus parcelas en usufructo. El proceso empezó en la zona de El Espinal alrededor de 1945, pero el desplazamiento más notorio ocurrió en la zona de Saldaña en los años 1951 y 1952 con la gran inversión en irrigación que propició el cultivo del arroz en gran escala. Algunos campesinos de las haciendas fueron "reubicados" mediante compra en las tierras menos aptas para la agricultura comercial. La gran mayoría de los campesinos fueron desvinculados totalmente de su acceso a la tierra formando la base de un proletariado agrícola radicado en pequeños núcleos semiurbanos.

El proceso de producción en los cultivos comerciales se caracteriza por su alto modo de mecanización, que implica poco uso de mano de obra permanente, al mismo tiempo que una gran demanda de mano de obra temporal en determinadas épocas del ciclo agrícola. Los desplazamientos masivos de campesinos fueron la base de esta masa de reserva de mano de obra para servir a los intereses de la agricultura comercial. La proletarización campesina se caracterizó, tanto por la proletarización masculina como femenina en relación con la demanda intensiva de mano de obra en ciertos períodos del año. Así encontramos que las mujeres, cuando la mano de obra masculina aparentemente no abastece los requerimientos del cultivo, se involucran en el proceso productivo en los desyerbes de algodón y ajonjolí, así como también en la época de cosecha de estos productos.

La legislación agraria de 1936, como la de 1961, respaldó el interés de los nuevos empresarios agrícolas, ya que la mano de obra atada a la tierra restringía el desarrollo del mercado libre de trabajadores, además de su propio acceso a la tierra. En las zonas donde el auge comercial no fue tan profundo, las leyes agrarias previas a 1960 no tuvieron tanta importancia y se siguió, en buena medida, el sistema de hacienda con arrendatarios (zona de San Luis).

Fue tal vez el impulso estatal, en combinación con las reivindicaciones campesinas producidas por la violencia, lo que originó en cierta medida la descomposición de la hacienda. El mercado de tierras mostró en esta zona, de menor impulso en la agricultura comercial, un bajo desarrollo que sirvió como condición para la creación — vía la reforma agraria— de un sector de campesinos propietarios de parcelas,, quienes en parte pasaron 
también a responder a los estímulos del mercado interno vinculándose al mercado de productos. Sin embargo, cuando el acceso a la tierra es insuficiente para reproducir las necesidades de consumo familiar, este campesinado se semiproletariza y forma parte de la reserva de mano de obra de las fincas capitalistas.

El auge de la agricultura comercial trajo consigo el desarrollo local de industrias de transformación (desmotadoras de algodón, industrias de producción de insumos agrícolas, molinos de arroz, industria textil) como sucedió en Texpinal en 1975. Estas industrias aprovechan no sólo la cercanía a su materia prima sino también la oferta de mano de obra de trabajadores desligados de la tierra. Parte de la demanda de mano de obra ha sido satisfecha por mujeres. La división del trabajo dentro de la fábrica tiende a mantener una mano de obra barata y cuando ésta es para oficios manuales intensivos se ocupan mujeres y se les pagan sueldos inferiores a los de los hombres que se utilizan en otras tareas.

El proceso del desarrollo capitalista en el agro propició, entre otros, una serie de efectos que caracterizan la zona en la actualidad:

1. El acelerado ritmo de crecimiento de la población urbana en comparación con la rural, debido a la expulsión de los campesinos de las haciendas;

2. Una nueva estructura agraria caracterizada por lotes de cultivos comerciales, en su mayoría de 50 a 100 hectáreas, muy tecnificados y mecanizados;

3. Una reducida demanda de mano de obra permanente en la agricultura, casi siempre masculina, y una gran demanda de mano de obra temporal abastecida tanto por el proletariado urbano como por el campesinado semiproletarizado en minifundios que rodean las empresas capitalistas, $\mathrm{y}$

4. Una marcada diferenciación campesina entre los que venden y compran mano de obra.

En todos los estratos del campesinado se da la participación ferhenina en la agricultura familiar. La mujer participa en casi todas las actividades agrícolas como la siembra, distanceo,, desyerbe, corte y sacudida de ajonjolí, y en casi todos los cultivos —algodón, ajonjolí, plátano, yuca, maíz y tabaco. Sin embargo, su participación es casi siempre en calidad de ayudante de su esposo, padre o hijo mayor. El hombre es siempre el agricultor de la familia y tiene la iniciativa en las decisiones y en la dirección del trabajo.

Hay evidencia de que cuando la mujer participa en la agricultura familiar, lo hace en las mismas tareas agrícolas, cualquiera que sea su estrato. Sin embargo, a más bajo estrato mayor participación de la mujer. Por lo tanto la participación femenina se relaciona con el tamaño de la parcela y la capacidad de la unidad familiar para contratar mano de obra asalariada y de esta manera con la posición socioeconómica de la familia. 
Cuanto mayor es la unidad agrícola, se acentúa más la tendencia a la agricultura comercial complementada con ganadería. La ganadería continúa como actividad masculina pese a que la mujer se encarga del ordeño y muchas veces del pastoreo, además de alimentar a los animales, tareas en las cuales es ayudada por los niños. La necesidad de mano de obra en los cultivos del estrato alto destaca la elevada participación de mano de obra asalariada, aparte de la del hombre de la familia. En unidades familiares medianas también se requiere mano de obra asalariada para la producción de productos comerciales, aunque dentro de este grupo hay mayor preferencia por productos de "pancoger" en combinación con la agricultura comercial, ya sea algodón, arroz o tabaco. Dentro de este grupo la mujer participa más en las actividades de cosecha.

Es en el sector bajo del campesinado en donde con mayor frecuencia se combínala agricultura de productos de "pancoger" para el consumo familiar con algo de cultivos comerciales. Aquí el uso de mano de obra asalariada es mínimo y se da una utilización intensa de mano de obra familiar en el proceso productivo, representado en parte por la mujer y los hijos. Es también en las unidades familiares bajas donde se da el más alto grado de proletarización, sea masculino o femenino. El hombre vende su fuerza de trabajo a campesinos con más tierra, así como también a empresas capitalistas, según el ciclo agrícola. La mujer sale a trabajar en actividades donde la contraten pero en particular en la cosecha del algodón. Es claro que la mujer sale a trabajar como asalariada debido a las necesidades económicas familiares, pues en estratos con mayores posibilidades económicas el trabajo asalariado femenino es menor. Para el hombre del estrato medio, la semiproletarización es importante.

Hay además una estrecha correspondencia con el nivel ideológico de lo que debe o no hacer la mujer en cuanto a trabajo fuera de la unidad familiar. Se nota que el trabajo asalariado de la mujer "avergüenza" al hombre y es solamente la necesidad económica la que impulsa a la mujer a trabajar fuera. Se puede plantear que, tal vez, estos rasgos ideológicos demuestran la influencia importante del sistema de hacienda en años anteriores. Hay que notar que la mayoría de los campesinos independientes de hoy día participaron, ya sea por sus padres o por ellos mismos (pero en menor grado), en relaciones con la hacienda. Dentro de la hacienda era el hombre quien cumplía con las obligaciones frente al hacendado en la producción directa, aunque la mujer y los niños participaban en las tareas agrícolas dentro de la parcela familiar. Hoy día estos rasgos se manifiestan en el hecho de que la participación de la mujer en la agricultura familiar sea totalmente aceptable; pero es el trabajo de la mujer como asalariada en la agricultura el que tiene repercusiones a nivel ideológico. La mujer trabaja a jornal principalmente en la cosecha de algodón en una época del ciclo agrícola donde la mano de obra masculina está totalmente ocupada. Se ve que en cultivos como el arroz hay una marcada limitación de la participación femenina como asalariada, pero al mismo tiempo este cultivo requiere muy poca mano de obra y tiene su mayor desarrollo en la 
época del año en que hay poco trabajo masculino. En este cultivo de riego se encuentra a nivel valorativo un refuerzo de la base material del mercado de trabajo ai aparecer culturalmente la noción "el agua hace daño a la mujer", y es por esto que no trabaja.

En la agricultura comercial existen mejores oportunidades de empleo para la mujer en la industria de procesamiento de tabaco. Para las mujeres que viven cerca de la fábrica hay la posibilidad de trabajar unos cinco o siete meses del año, aunque la demanda no llega a cubrir la cantidad de mujeres rurales que tienen necesidad de emplearse para contribuir al mantenimiento familiar. En fecha reciente,, el establecimiento de una fábrica de hilazas ha creado otra oportunidad de empleo femenino. Como en el caso del procesamiento del café, la división del trabajo dentro de la fábrica se ha previsto para mantener el salario de la mujer a un nivel más bajo que el masculino. Por lo tanto, se han establecido tipos de trabajo para los cuales se contratan básicamente mujeres. Está política en la fábrica textil cambió después de un año debido a la elevada tasa de ausencia de mujeres por causas familiares. Por lo tanto la empresa prefiere mujeres jóvenes y solteras, para evitar que problemas como el embarazo, que se definen como femeninos, no influyan en la productividad.

Para la mayor parte de las mujeres rurales la alternativa principal de empleo se encuentra en el servicio doméstico, el cual requiere que la mujer emigre, lo que resulta imposible para la mayoría de las madres de familia. Por esta razón, dentro de las unidades del campesinado bajo, existe una acentuada tendencia a que emigren las hijas de la unidad en cuanto puedan conseguir trabajo, y es la madre de familia quien se encarga junto con el padre de la producción parcelaria. Tanto el uno como el otro salen como proletarios o semiproletarios cuando hay trabajo para complementar la subsistencia familiar con el salario. Las mujeres y los hombres, ligados a la tierra pero sin posibilidades de satisfacer sus necesidades de consumo con la propia producción, forman una reserva de mano de obra. Como ya se describió,, es en particular la mujer quien entra al mercado de trabajo en forma de reserva cuando la oferta de mano de obra masculina no cubre la demanda.

\section{El proceso de la región de García Rovira}

Como ya se señaló, las zonas estudiadas entraron a la economía nacional con el desarrollo de la economía exportadora, así como también con el proceso de industrialización nacional que emergió al desarrollarse el mercado interno. Al mismo tiempo el desarrollo del capitalismo en el país, como forma dominante, dejó otras zonas en un profundo estancamiento. Tal es la historia económica de lá zona de García Rovira, ubicada en Santander del Sur.

Parece ser que esta zona se caracterizó, desde principios del siglo $\mathrm{xx}$, por una estructura agraria de pequeños propietarios, como fuente de expulsión de mano de obra, y por una débü proyección en la economía 
nacional en cuanfo a la demanda de sus productos. Ya para los primeros decenios se ven rasgos que inciden en su actual situación. En el período de 1896 a $1912^{20}$ la zona expulsaba mano de obra. El período posterior a la primera guerra mundial parece haber traído un florecimiento y el campesinado se vinculó al mercado de productos por medio del trigo y la ganadería en las tierras frías, y al tabaco y la caña de azúcar en las más cálidas. Parece ser que en este tiempo la zona pudo ofrecer empleo para su fuerza de trabajo en la producción agrícola y en las obras públicas, principalmente de caminos, que caracterizó la construcción de la infraestructura del país previa a 1930. Esta expansión decayó en el período de la depresión (1929-1932) que internamente se manifestó en la falta de oportunidad de trabajo, lo que tal vez unido a la primera etapa de violencia del país, con incidencias en la región, crearon una presión sobre la tierra. Durante el período de la segunda guerra mundial,, la producción de trigo vinculada al creciente mercado interno fue un factor dinámico que posteriormente se vio frenado por la competencia en la producción nacional por la importación de harina de trigo de Estados Unidos a precios subsidiados, fenómeno que para los años de 1955 significó el debilitamiento de la integración de la región a la economía nacional.

García Rovira, en comparación con otras zonas del país, no se caracterizó por la gran hacienda. A comienzos del siglo xx la estructura agraria mostraba el predominio de la pequeña parcela, muchas veces bajo la forma de propiedad y otras en forma de aparcería. Se plantea a manera de hipótesis que la extracción del plus producto a través de la renta de la tierra, que se da en la aparcería, sirvió para reproducir la burguesía agraria de la zona, muchas veces de base urbana. El sistema de aparcería se reflejó también en una marcada diferenciación campesina. Por un lado, los que tenían suficiente tierra para entregar a aparceros, y por otro, la creciente masa de campesinos a quienes les quedaba como alternativa migrar de la zona definitivamente o concertar arreglos de aparcería para tener acceso a la tierra. Para 1912 una cuarta parte de la población rural estaba constituida por aparceros y arrendatarios, cifra que se mantiene hasta los primeros años del decenio de 1960.

Aun cuando las relaciones señoriales no fueron la característica predominante de la zona, sí se encuentran rasgos de relaciones serviles entre la clase poseedora de tierra y la que carecía de ella. Así, podría decirse que los arreglos de aparcería, previos a 1960 y de modalidades muy variadas, se caracterizaban por el usufructo de la parcela y en algunos casos de la vivienda por parte del aparcero, quien recibía la semilla, debía poner el trabajo y pagar la renta con la mitad del producto. Se menciona que tam-

\footnotetext{
${ }^{20}$ Aunque las cifras censales para la época han sido puestas en tela de juicio por diversos problemas técnicos, es indicativo que los cálculos del crecimiento de población para la zona entre 1896 y 1912 sólo arrojan un $0.3 \%$ de crecimiento, cifra que permite deducir la existencia de una migración permanente. Este dato y algunos aspectos del análisis aquí consignado se apoyan en: Ramón Crouch y Alain de Janvry, "Breve historia agrícola de la Provincia de García Rovira". Bogotá, septiembre de 1977 (Mimeo).
} 
bien había obligaciones para la hacienda; la más general era que el hombre de la familia trabajara gratis un día a la semana para el dueño de la tierra y que la mujer campesina se encargara del cuidado de los animales del dueño de la tierra, ya fuera el pastoreo o el ordeño, además de cumplir con servicios domésticos cuando fueran requeridos. ${ }^{21}$

La entrada de la Compañía Colombiana de Tabaco en la zona, a finales del decenio de 1920, aseguró un mercado local para el tabaco, factor que posiblemente aumentó el número de parcelas bajo aparcería para la producción de este producto en las tierras aptas para su cultivo. Este producto se caracteriza por el uso intensivo de mano de obra, el cual al ser producido por la familia campesina asegura la extracción del plus producto a través del trabajo de mujeres, niños y hombres.

Con la reforma agraria de 1961, los rasgos mas tradicionales de la relación de aparcería, como obligaciones, han ido desapareciendo y los arreglos, por lo menos en términos legales, se han vuelto más formales. En algunos casos la reforma impulsó la expulsión de los aparceros, pero más general fue la tendencia a negar el uso de casa en tierra del dueño y a combinar, en el caso de los mismos campesinos, el uso de la aparcería con la explotación directa, o, en el caso de pequeña burguesía urbana, con la administración delegada de mayordomos.

La característica sobresaliente de la zona en la actualidad es una agricultura de parcelas, en su mayoría de una a tres hectáreas, ya sea en propiedad o en aparcería, que cubren sólo en parte las necesidades de consumo de la familia. Dado el reducido desarrollo del mercado de trabajo local, para cubrir sus necesidades la familia depende en parte de la migración temporal, en especial a Venezuela. A su vez, el escaso desarrollo del mercado de trabajo y su débil vinculación a la economía nacional a través del mercado de productos de la zona, se manifiestan en un reducido grado de monetarización,, lo cual se refleja parcialmente en el uso intensivo de la "mano vuelta" o intercambio de trabajo por trabajo, así como también en el poco desarrollo del trabajo asalariado entre las diferentes capas del campesinado.

La alternativa campesina de migrar de manera definitiva y el escaso desarrollo de un mercado de trabajo en la zona pueden ser, entre otros, factores que ayuden a explicar la persistencia de la aparcería en la agricultura, como manera estructural de atar mano de obra a la tierra y de percibir los propietarios una renta.

La participación de la mujer en la producción agrícola está estrechamente ligada al tamaño de la parcela y al tipo de producción. La actividad agrícola sobresaliente de la mujer en todos los grupos del campesinado se da en la siembra y en la cosecha. Además, la mujer se ve obligada a dedicarse a la preparación de dos a cuatro comidas diarias, que son parte

\footnotetext{
${ }^{21}$ Entre las relaciones de explotación, fue contado por un informante que existió la costumbre del dueño de la tierra de tener "derecho a la primera noche" con las hijas del aparcero, o de pagarle a la familia para llevarse a su hija por un tiempo o para ponerla en su casita.
} 
de la remuneración en especie dada a los peones contratados como mano vuelta. Esta obligación aumenta con el tamaño de la parcela, ya que esto significa incremento de mano de obra. Por otro lado, en las parcelas más pequeñas la producción tiende a realizarse con la mano de obra familiar, con lo cual aumenta la participación de la mujer y de los niños en el trabajo de campo. En el cultivo del tabaco, la participación femenina es más destacada. La mujer es la que se encarga de los semilleros y muchas veces efectúa la siembra. La cosecha, aunque continua, en la época más fuerte es intensiva en el uso de mano de obra y obliga en muchos casos a familias enteras a dedicarse a la tarea. La pica y ensarte de tabaco son también tareas caracterizadas por una gran participación femenina. Se encontró además que, dada la necesidad de complementar la producción agrícola con ingresos generados fuera de la unidad familiar y muchas veces logrados por la migración temporal, la mujer se encarga de la parcela agrícola cuando el hombre sale.

El escaso trabajo asalariado que se genera en la zona a nivel rural, se da principalmente en el tiempo de cosecha de tabaco y en la producción de caña, y es de tipo temporal. Se contrata en los cultivos más grandes, pero también a nivel de aparcero quien en ocasiones requiere de mano de obra extra. A nivel rural se destaca como fuente de trabajo estable, aunque sólo unos cinco meses al año, la Compañía Compradora de Tabaco, la Colombiana, que tiene en la zona su planta de selección y empaque. Aun en las épocas más intensivas de producción, la Compañía en una de sus dos bodegas sólo llega a emplear 150 personas, en su mayoría mujeres provenientes de la vecindad rural. A nivel urbano, sobre todo en Málaga, además de la prestación de servicios, se encuentra como fuente de trabajo la artesanía en tejidos y una incipiente manufactura que surte la zona fronteriza con Venezuela. Este mercado de trabajo, de perfiles muy femeninos, depende en parte para su ampliación o aniquilación de la competencia de los productos que ofrece - suéteres y ropa de vestir- en el mercado de la región, en especial el de Cúcuta. Estas fuentes de trabajo,, si bien es cierto que estimulan la migración de la zona rural a la zona urbana a nivel local, también pueden servir de freno a las corrientes migratorias al encontrar ingresos adicionales en la misma zona, o representar para otros sólo una etapa intermedia en su proceso migratorio.

El monopolio de compra de tabaco por parte de la Colombiana determina que la mayoría de los campesinos en la tierra baja estén indirectamente bajo su explotación a través del mercado. Se cultiva el tabaco por ser éste el único producto con mercado estable, o porque así lo determina el dueño de la tierra, en el caso de la aparcería. Además, la Compañía provee insumos para el cultivo, con lo que genera endeudamiento, aunque impulsa la siembra y la dedicación de la mano de obra al mismo. La explotación que la pequeña burguesía agraria hace de la mano de obra en la producción de tabaco, por medio de la aparcería, se estimula porque el tabaco resulta un producto seguro para cultivar con aparceros (por no ser comestible), lo que disminuye el riesgo de ser consumido cürectamen- 
te, al tiempo que por ser cultivo con un gran requerimiento de mano de obra, la familia como totalidad responde ala producción, lo cual permite mantener la tasa media de ganancias a través de la extracción de plusvalía absoluta.

García Rovira presenta un caso de bajo desarrollo de las fuerzas productivas que, unido a otros factores, ha llevado a un estancamiento. Éste recae sobre la familia campesina sujeta a formas de extracción de excedentes basadas en relaciones de aparcería, así como también sujeta a relaciones con el capital mercantil monopolista, donde los precios de la mercancía no reflejan su valor. Para la familia campesina, la semiproletarización es una forma de sobrevivencia temporal. El hombre migra de la zona y la mujer trabaja lo que puede en el tabaco. Para los hijos, la alternativa es la migración permanente fuera de la zona. De otra manera, la integración de García Rovira al sistema nacional se caracteriza por la producción de mano de obra, y a nivel local por la extracción de plus producto para la acumulación de la burguesía agraria local y por intermedio de ésta, o directamente, para la acumulación del capital mercantil.

I I I . RESUMEN FINAL: EL TRABAJO DE LA MUJER RURAL Y EL DESARROLLO DEL CAPITALISMO EN EL AGRO

El interés esencial de este ensayo ha sido el de formular los rasgos más generales del proceso del desarrollo del capitalismo y su significado en cuatro diferentes regiones de Colombia, en un intento por entender, dentro de este marco, las implicaciones que se derivan para la división sexual del trabajo.

El análisis del desarrollo del capitalismo en cuatro regiones de Colombia ilustra tres diferentes formas de integración regional a la economía nacional. En primer lugar, a través de la producción de una mercancía para el mercado internacional,, en segundo lugar mediante la producción capitalista como respuesta al desarrollo del mercado interno y, por último, mediante la función de proveer mano de obra. A cada forma de integración corresponde una estructura agraria particular y un proceso interno de cambio en las relaciones de producción, con repercusiones importantes para la economía campesina. Las regiones de El Espinal y Sincelejo, a medida que se desarrolla la economía capitalista, se caracterizan por el proceso de capitalización de las haciendas en cuanto se desarrolla el mercado de tierras y se proletariza la mano de obra y éstas se transforman en empresas capitalistas para responder a las crecientes demandas del mercado interno. Además este proceso se complementó por la entrada de nuevos capitales al sector agrario, toda vez que el mercado de tierras permitió romper con parte del monopolio de las grandes extensiones de tierra o la compra a pequeños propietarios. La consecuencia sobresaliente de este proceso fue la proletarigación del campesinado, que vino a cumplir la función de reserva 
de mano de obra para satisfacer la demanda estacional que caracteriza la agricultura comercial.

En contraste, el desarrollo capitalista en la región de Fredonia, que se logra al integrarse el país al mercado internacional con la producción del café, se caracteriza por un proceso más temprano de proletarización, así como también por el surgimiento de un sector campesino productor de mercancías. La integración de la región lograda a través de la producción de un producto intensivo en el uso de mano de obra, permitió que el campesinado experimentara un ciclo constante de diferenciación dinámica, fenómeno este que contrasta con la descomposición campesina de las zonas de El Espinal y Sincelejo.

Por otro lado, así como en Fredonia la integración del campesinado a la producción de mercancías por medio del café hizo posible el surgimiento de una capa media (farmer) de productores capitalistas, la región de García Rovira representa la antítesis de este fenómeno. Puede formularse como hipótesis que el desarrollo capitalista de otras regiones del país ha permitido reforzar la función de García Rovira como productora de fuerza de trabajo, dado su estancamiento relativo y su minifuridación. Sin duda, la región también genera un plus producto, que en parte es apropiado por el capital comercial y en parte permite la reproducción de una burguesía local. La región acusa una situación ecológica en extremo dramática y un sistema infraestructural bastante pobre, que inciden en las reducidas posibilidades de sus productos para competir en el mercado interno. Éstos, entre otros factores, han reforzado el bloqueo al desarrollo de las fuerzas productivas que permiten la reproducción de formas de producción, como la aparcería, como la forma variable de la pequeña burguesía local de mantener su coherencia y del capital comercial de absorber parte del plus producto.

Sobre este punto cabe preguntarse: ¿cuáles han sido los efectos de las diferentes armas de desarrollo capitalista para el trabajo de la mujer? En primer lugar es sobresaliente la manera como la apropiación del plus trabajo, bajo relaciones de producción no capitalistas, ha recaído sobre la familia campesina como unidad de producción, y por lo tanto, como unidad sujeta a la explotación. También debe resaltarse el papel que cumplió la familia para abrir la frontera en las regiones de Sincelejo y El Espinal. Es un caso de apropiación del trabajo en forma indirecta en el sentido de que correspondió a la familia abrir la selva, al adaptar las tierras al cultivo, y fue el valor incorporado a la tierra por el trabajo el que sirvió para la acumulación de la clase propietaria.

Es también en sí el sistema de hacienda el que permite apreciar diferencias en la división del trabajo por sexo, según la forma de integración de cada zona a la economía regional o nacional y según los requisitos de trabajo que implica cada producto. En Sincelejo y El Espinal los albores del siglo xx se caracterizaron por el control monopólico sobre la tierra por parte de una clase terrateniente dedicada a la ganadería extensiva. Arreglos muy variados fueron usados en ambas regiones para asegurar la mano de obra necesaria para la producción ganadera, así como la apropiación del plus 
producto en renta, especie, o por medio de la aparecería. Característico de ambas regiones es el hecho de que los servicios del trabajo recayeron sobre el hombre de la familia. Fue así como la explotación ganadera se dio mediante el uso predominante del trabajo no pagado. La familia campesina, basada en su propia fuerza de trabajo, necesitó producir lo necesario para su subsistencia. Esta estructura de producción permite señalar, a manera de hipótesis, que la mayor o menor participación de la mujer en la producción agrícola estaba directamente relacionada con el tiempo requerido del hombre por la hacienda. Además, es preciso indicar que el pago de renta en especie y los arreglos de aparcería también recayeron sobre la familia como unidad de producción. En Sincelejo parece que la participación de la mujer en la producción de subsistencia fue reducida, mientras que la producción de tabaco, que implica una amplia demanda de mano de obra, su participación fue grande, así como la de los niños, en especial en el procesamiento.

En cambio, la introducción del café en Fredonia permitió la activa utilización de la mano de obra familiar en casi todos los aspectos del proceso productivo. En las haciendas donde la producción de café estaba bajo el control directo del hacendado, la mujer y el hombre trabajaron en sus respectivas cuadrillas en casi todas las tareas. En la parcela de usufructo individual, la familia sujeta a la apropiación de su trabajo excedente fue la base de producción.

A pesar de que el sistema de grandes haciendas no parece haber jugado un papel fundamental en la región de García Rovira, la presión por la tierra empujó a muchas familias campesinas a entrar en relaciones no capitalistas con la clase terrateniente. Parece que las obligaciones de trabajo recayeron sobre la familia como un todo, aunque una acusada división de trabajo por sexo se presentó en la prestación de los servicios. El hombre trabajaba en la agricultura, mientras que la mujer prestaba servicios domésticos, así como también cuidaba de los animales.

El desarrollo de empresas capitalistas en el campo cambió de manera significativa las normas de trabajo y trajo consigo repercusiones en la división del trabajo por sexo. La integración de El Espinal al mercado interno, caracterizada por la entrada de nuevos capitales al agro y la capitalización de las haciendas, trajo como consecuencia la expulsión masiva de campesinos de sus parcelas de usufructo, creándose, por una parte, una reserva de mano de obra semiurbana de base rural y, por otra, un sector semiproletarizado de minifundistas. La mecanización de muchos de los procesos de la producción comercial trajo como consecuencia una limitada demanda de trabajo permanente en la agricultura, y quienes suplieron esta demanda fueron principalmente hombres.

La demanda estacional de trabajo temporal, en particular en la cosecha de algodón, resultó ser una oportunidad para la proletarización de la mujer. La mujer en el sistema de hacienda no participó en el proceso productivo directo, más bien parece haberlo hecho en la producción agrícola de sus propias parcelas. A pesar de no conocérsele trabajo fuera del hogar, la 
falta de acceso a los medios de producción, así como también el creciente empobrecimiento del sector bajo del campesinado, ha requerido que la mujer entre al mercado de trabajo, aunque en forma temporal. En el área tabacalera, las mujeres participan por un salario tanto en las actividades temporales de la recolección y el procesamiento como en la transformación industrial. Es reciente la existencia de oportunidades de trabajo en los textiles, facilitando estos cambios una ampliación de las posibilidades de proletarización femenina.

En contraste, en Sincelejo, donde la disolución de la hacienda es un fenómeno más reciente, tal vez de los últimos 20 años, la entrada de la mujer al trabajo agrícola como asalariada no es importante. Su participación en la cosecha del algodón se considera esporádica, en contraste con los grupos de mujeres y niños que participan en el Tolima. Sin embargo,, en el procesamiento del tabaco, una actividad que por tradición se ha identificado como trabajo femenino, la destrucción de la industria familiar y de los pequeños talleres de producción de cigarros ha dado paso a la proletarización femenina dentro de empresas industriales que surgieron.

El desarrollo de un activo mercado de trabajo en Fredonia se ha caracterizado por el aumento de la proletarización masculina entre trabajadores permanentes, en todo tipo de explotaciones, mientras que la participación femenina se ha restringido a las labores más intensivas en el uso de mano de obra, en la producción, así como también a ciertas tareas de procesamiento como la selección del café.

En García Rovira la ausencia de un mercado de trabajo desarrollado ha obligado al aumento de la migración temporal masculina y, de manera paradójica, dentro de la zona, las oportunidades de empleo que han resultado como consecuencia del procesamiento del tabaco y la producción manufacturera han dado oportunidades de empleo tanto permanentes como temporales principalmente a mujeres, con lo cual es probable que se haya reforzado la corriente de migración permanente de la mujer a las áreas urbanas.

Como un todo, los estudios de caso regionales, aunque representan marcadas diferencias en el proceso de desarrollo capitalista, dan base para formular la hipótesis de que la mujer, en el sistema capitalista, juega un papel de reserva de mano de obra ya sea en las haciendas, en las empresas capitalistas o en las unidades campesinas que emplean trabajadores. La proletarización femenina, desde el punto de vista de la demanda, ha estado relacionada de manera estrecha con el tipo de cultivos más intensivos en el uso de mano de obra. El uso de la mano de obra femenina está relacionado con dos factores que se combinan entre sí: el sostenimiento de salarios bajos, y la posible explotación que se pueda hacer del trabajo familiar. En este fenómeno tampoco debe descartarse el uso del trabajo femenino cuando escasea la oferta por parte del hombre, dada la existencia para él de otras oportunidades alternativas, con lo cual la proletarización femenina contribuye a mantener bajas retribuciones al capital. Si las relaciones de producción no capitalistas tienden a ubicar la explotación a 
nivel de la familia, las relaciones de producción capitalistas, en contraste, tienden a ubicar la explotación en forma directa en el individuo. Sin embargo, una característica del uso de la fuerza de trabajo femenina en la agricultura capitalista ha sido el incentivo dado al inducir el trabajo de los hijos junto con el de la mujer, ya que a ella se le paga a destajo. El pago por la cantidad de trabajo realizado ha servido para aumentar la jornada diaria de trabajo, así como también para estimular a la familia como conjunto a participar en la actividad para poder ganar lo que podría constituir un salario apropiado.

En las empresas industriales la función que tiene el trabajo femenino - con salarios reducidos - para mantener bajo el salario general, se evidencia en las tareas segregadas por sexo, o territorios sexuales. El salario femenino permanece por abajo del salario masculino dado que las tareas que cumplen las mujeres son consideradas menos pesadas y que demandan menor esfuerzo de trabajo.

Desde el punto de vista de la oferta, la proletarización de la mujer ha estado relacionada de manera estrecha con la necesidad económica. La mujer entra a la fuerza de trabajo en el sector rural, pese a que existen valores culturales negativos, ante la necesidad de contribuir a la subsistencia familiar. 